Portland State University

PDXScholar

$5-11-1983$

\title{
The Correlation Between Expressive Language Delay in Children and Their Motor Abilities
}

Gail G. Cunningham

Portland State University

Follow this and additional works at: https://pdxscholar.library.pdx.edu/open_access_etds

Part of the Child Psychology Commons, Motor Control Commons, and the Speech Pathology and Audiology Commons

Let us know how access to this document benefits you.

\section{Recommended Citation}

Cunningham, Gail G., "The Correlation Between Expressive Language Delay in Children and Their Motor Abilities" (1983). Dissertations and Theses. Paper 3241.

https://doi.org/10.15760/etd.3233

This Thesis is brought to you for free and open access. It has been accepted for inclusion in Dissertations and Theses by an authorized administrator of PDXScholar. Please contact us if we can make this document more accessible: pdxscholar@pdx.edu. 
AN ABSTRACT OF THE THESIS OF Gail G. Cunningham for the Master of Science in Speech Communication with an emphasis in Speech-Language Pathology, presented May 11, 1983.

Title: The Correlation Between Expressive Language Delay in Children and Their Motor Abilities.

APPROVED BY MEMBERS OF THE THESIS COMMITTEE:

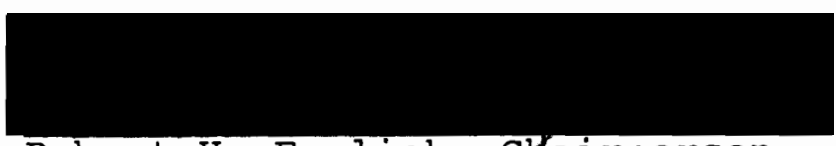

Robert H. English, Chairperson

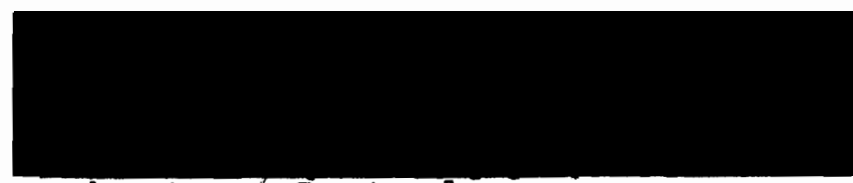

Robert L' Casteel

Lenneberg (1967) noted that as a child matures a general growth pattern is observed with both language skills and motor skills co-developing. Most of the research relating to motor skills deals with articulation skills, oral diadokokinetic rates, learning disabilities, and intelligence. 
Relatively few studies, however, appear to correlate motor skills with expressive language delay in children.

The purpose of the present study was to determine the correlation between expressive language delay in children and their gross and fine motor skills. Twenty children five years through six years, eleven months with a diagnosed expressive language delay, were selected to participate in the study. Each was screened on the basis of normal hearing, receptive vocabulary skills, motor functioning, and an expressive language delay of one year or more. After screening procedures, each child was administered the Preschool Lanquage Scale-PLS (Zimmerman, et al., 1969) and the short form of the Bruininks-Oseretsky Test of Motor Proficiency-BOMP (Bruininks, 1978). The data were analyzed using a Pearson Product-Moment Correlation along with means, standard deviations, and a one-tailed $\underline{t}$-test of significance.

According to the data results, the standard Score, an overall measurement of the children's motor skills, indicated a moderate inverse correlation, $r .=-.41$, while the Total Point Score, r. $=-.17$, and the Percentile Rank, r. $=-.28$, had weak inverse correlations. In relation to the individual test items, negligible correlations were indicated in the gross motor items, with the exception of "Walking Heel-toToe" and "Catching a Tossed Ball," which obtained positive correlations, $r_{.}=+.13$ and +.30 , respectively.

There were three out of six fine motor tasks with low to moderate inverse correlations: "Copying a Circle" 
generated a moderately-strong inverse correlation, $r .=-.48$; "Copying Overlapping Pencils" and "Response Speed," posted low inverse correlations, $r_{0}=-.37$, and $r_{.}-.24$, respectively. A one-tailed t-test revealed subjects performed these three items more poorly than the gross motor and some fine motor tasks on the BOMP. The expressive language delayed children tended to have deficits in manual dexterity tasks but not in gross motor tasks.

The results obtained from the present study were compatible with the research conducted by sprague (1961) and Wolff and Wolff (1972). Both investigators found significant correlations between fine motor tasks and expressive language. Negligible correlations were indicated between gross motor skills and expressive language. It was concluded by the present investigator that children with expressive language delay might have deficient fine motor development. 
THE CORRELATION BETWEEN EXPRESSIVE LANGUAGE DELAY IN CHILDREN AND THEIR MOTOR ABILITIES

by

GAIL G. CUNNINGHAM

A thesis submitted in partial fulfillment of the requirements for the degree of

MASTER OF SCIENCE IN SPEECH COMMUNICATION:

with an emphasis in

SPEECH-LANGUAGE PATHOLOGY

Portland State University

1983 
TO THE OFFICE OF GRADUATE STUDIES AND RESEARCH

The members of the committee approve the thesis of

Gail G. Cunningham presented May 11, 1983.
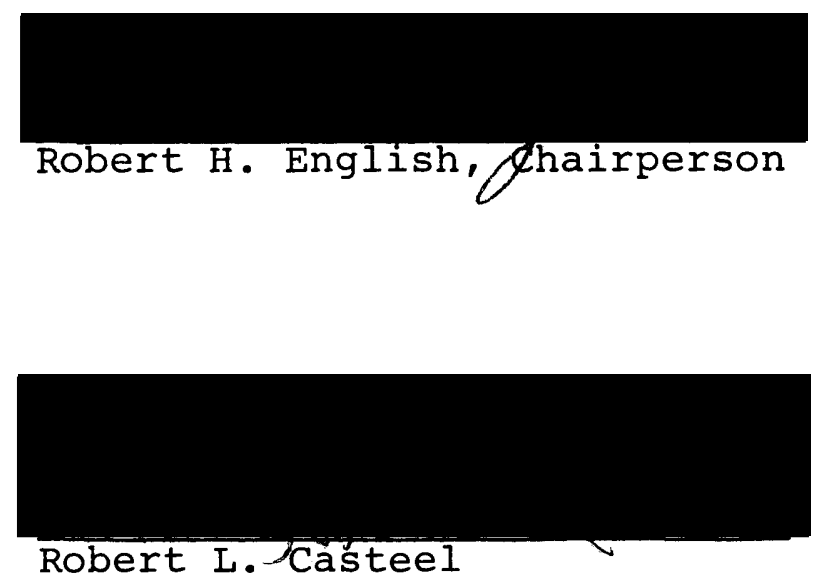

APP ROVED :

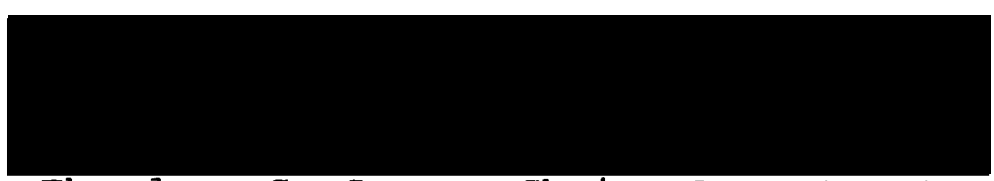

Theodore G. Grove, Chair, Department

of Speech Communication

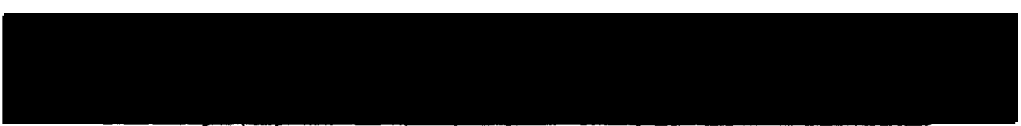

Stanley E. Rauch, Dean, Graduate

Studies and Research 


\section{ACKNOWLEDGEMENTS}

As I reflect back on the task of producing this thesis, there were endless amounts of hours spent researching, writing, revising, more revising, typing, and running the study. The following people deserve special recognition for their direct and indirect assistance.

I am very grateful to the members of my committee, especially Dr. E. It has been an honor and pleasure to have had you as my graduate advisor and thesis director. I appreciate your encouragement, direction, and personal concern during these past two years. Dr. Casteel, thank you for your contributions and criticism during the initial phases of the thesis. Your input as a member of my committee was of much value. I also wish to thank Ted Grove for his efforts in explaining the statistical interpretation of the data. Thank you everyone!

A special note of recognition goes to my closest, dearest friend and roommate, Marie Cunningham, who was by my side through the best and worst of times. I am especially thankful for her endless amount of patience, support, encouragement, and words of wisdom. Marie was always ready and willing to listen to my problems and frustrations. I give many, many thanks for "Mer" being such a special friend to me.

I also need to thank my family for providing me with 
the opportunity to pursue my goals and enrich my life through education. Thank you for allowing me to share my experiences with you and for never losing faith in me during graduate school. All of the long distance calls, letters, hugs, and vacations to Albuquerque helped keep me sane! Mom and Dad, your youngest daughter finally made it!

Finally, I acknowledge my Lord for providing me with strength and wisdom during my education. As Isaiah 40:31 says, "But those who hope in the Lord will renew their strength. They will soar on wings like eagles; they will run and not grow weary, they will walk and not be faint." 
TABLE OF CONTENTS

Page

ACKNOWLEDGEMENTS

LIST OF TABLES

iii

vi

\section{CHAPTER}

I INTRODUCTION AND STATEMENT OF PURPOSE • • . 1

Introduction . . . . . . . . . . . . 1

Statement of Purpose . . . . . . . . . 2

Operational Definitions . . . . . . . 3

II REVIEW OF THE LITERATURE . . . . . . . . . 4

Historical Background . . . . . . . 5

Related Studies ... . . . . . . 8

Summary ....... . . . . . 12

III METHODS AND PROCEDURES . . . . . . . . . 13

Methods . . . . . . . . . . . 13

Procedures ............. 16

IV RESULTS AND DISCUSSION . . . . . . . . 20

Results .............. 20

Discussion . . . . . . . . . . . . 24

$\mathrm{V}$ SUMMARY AND IMPLICATIONS . . . . . . . 30

Summary . • . . . . . . . . . 30

Implications . . . . . . . . . 32

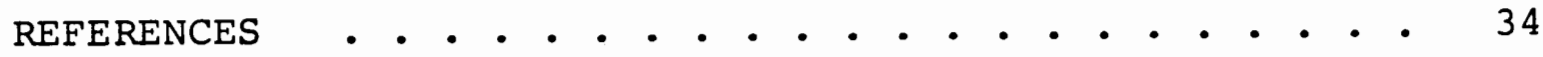

APPENDICES .................... . . 37 


\section{LIST OF TABLES}

TABLE

Page

I Mean and Standard Deviation of the Sample's

Chronological Age in Comparison to the Expressive Language Age Delay, Mean and Standard Deviation as Measured by the PLS

I Mean, Standard Deviation, Analysis of Correlation between the PLS and the BOMP, and t-test results . . . . . . . . . . .

III Point Score Ranges, Means, Standard Deviations, Correlation Coefficients, and t-test Results of the BOMP 
CHAPTER I

INTRODUCTION AND STATEMENT OF PURPOSE

\section{Introduction}

The theory of motor skills relating to linguistic abilities is not new. In 1880, Schultze hypothesized that children learn only one behavior at a time. While walking, the infant learns to push aside language development until the locomotor action is perfected (McCarthy, 1946). One of the more recently accepted theories among educators and researchers was postulated by Lenneberg (1967). According to his biological approach, as a child matures and develops there is a general growth pattern with both language skills and motor skills co-developing in early childhood.

Some researchers, such a Kephart, have a different approach in relation to language skills and motor skills. According to Kephart's theory (1960), higher forms of behavior, such as reading, writing, and speech, ". . develop out of and have roots in motor learning . . " These higher forms of behavior are dependent upon lower forms of behavior. A child's development may be blocked at particular stages and influence the child's performance and development at later stages. Breakdown occurs in the child's verbal development as well. 
Wolff and Wolff (1972) studied the relationship between motor activity and verbal activity in nursery school and kindergarten age children. Based on the ratings of their teachers, it was concluded that verbal output, or ". . the degree to which the child emits verbal material. . . is more highly related to gross motor activity. Verbal skills, or ". . the level of sophistication of the child's speech . . ." were significantly correlated with fine motor abilities and manual dexterity. This investigator interpreted these findings as positive correlations.

Most of the research relating to motor skills deals with learning disabilities, intelligence, and articulation skills. There appears to be relatively few studies, however, correlating motor skills and expressive language delay in children. It is important to determine whether or not a significant relationship exists.

\section{Statement of Purpose}

The purpose of this study was to determine the association between expressive language delay in children and their motor abilities. Two questions were addressed in this investigation:

1. Is there a significant relationship between an increased expressive language delay and reduced motor abilities in children with a language delay?

2. What specific gross and fine motor skills had the strongest association with language delay? 
Operational Definitions

The following are descriptions of specific terms used

in the investigation.

Expressive Language Delay: This term will refer to language which follows an orderly pattern of language development, but is not appropriate according to the chronological age (Bangs, 1968). For the purpose of this study, an "expressive language delay" will be where a child is at least one year delayed or more in expressive language abilities, as determined by the expressive portion of the Preschool Language Scale (Zimmerman, Steiner, and Evatt, 1969).

Gross Motor Skills: This term, as used in the study, will refer to the ability to contract large muscles and move the entire body. Gross motor skills will be assessed with the short form of the Bruininks-Oseretsky Test of Motor Proficiency-BOMP (Bruininks, 1978), using four subtests, including: Running Speech and Agility; Balance; Bilateral Coordination; and Strength.

Fine Motor skills: This term refers to precise movements performed by small muscles, especially those of the hands, fingers, and forearms. Fine motor skills also involve eye-hand coordination and manipulation of tools and small objects (Sage, 1977). Each subject's fine motor skills will be assessed with four subtests of the BOMP, including: Response Speed; Visual-Motor Control; Upper-Limb Speed; and Manual Dexterity. 


\section{CHAPTER II}

\section{REVIEW OF THE LITERATURE}

As humans, we have a natural propensity for communication, which includes both receptive (comprehension), and expressive (production) modes (Hopper and Naremore, 1978). Expressive language is described as the verbal interaction between individuals. The receptive mode involves mental processes, which integrates and associates the meaning of the message.

Language has a tremendous effect on a child's relationship between himself and his environment (Menyuk, 1971). Through language acquisition new behaviors are developed, including organized play and coordinated motor movements (Luria, 1961). Gradually, the child learns how to effectively use reasoning, mental planning, thought, memory, and imagery to influence his immediate environment. By the time a child reaches four years of age, he has acquired a system of verbal instructions to regulate his own behavior (Luria and Yudovich, 1959). Appropriate language development frees the child from dependence on immediate events in the environment and allows the child to act independently within the environment.

Luria (196I) noted that as a child's language develops, motor skills also are acquired. Historically speaking, researchers (Orton, 1937; Kephart, 1960; Barsch, 1966; 
Myklebust, 1971; and Delacato, 1973) have explored the relationship between language and motor skills. The following section briefly describes their hypotheses on this subject.

\section{Historical Background}

There is an hypothesized interrelationship between language and motor skills, which has been studied for several years with mixed results. Theories supporting this interrelationship are varied as well. Kephart (1960) and Barsch (1966) assumed higher forms of behavior (speech, reading, and writing) have roots in motor learning. On the other hand, researchers, including Orton (1937), Myklebust (1971), and Delacato (1973) focused on neurological factors influencing motor and language learning. Studies, thus far, have correlated motor skills with articulation skills, oral diadokokinetic rates, learning disabilities, mental retardation, intelligence, and academic studies. Investigations relating expressive language and motor behavior, however, are not apparent in the literature.

Theoretical Perspective

Motor theorists, Kephart (1960) and Barsch (1966), conducted extensive research describing motor factors which have an impact on learning. According to Kephart (1960), higher forms of behavior develop out of motor learning. Furthermore, Kephart (1960) states that children with learning disabilities have an unstable perceptual-motor world and are disorganized 
motorically, perceptually, and cognitively. A breakdown in motor acquisition will affect the child's performance in higher learning processes as well.

Barsch (1966) theorized motor efficiency to be an important variable in the development of language efficiency. Omission of certain motor experiences during infancy may result later in motor or learning difficulties.

In addition to the motor approach, other theorists including Orton (1937), Myklebust (1971), and Delacato (1973), hypothesized neurological factors affecting motor and language deficiencies. According to orton (1937), many children with mixed sidedness in motor skills could have comparable "integrading" (interpreted as mixed dominance in this investigation) between critical areas of the brain for various language abilities.

Myklebust (1971), also focusing on neurological aspects affecting motor and language skills, stated that children with language deficits are "clumsy." Their deficit is represented by a generalized neurological dysfunction. Although, a clearly defined type of deficit in the motor and sensory spheres does not exist.

Delacato (1973) theorized language and motor development to be a maturational process. Difficulties in these areas may be due to incomplete neurological organization. The failure to pass through sequences of development indicates poor neurological development and may result in problems of mobility and communication (Delacato, 1973). 
Shirley (1933), Gessell (1954), and Lenneberg (1967) discussed the relationship between motor and language development from a biological approach. Although earlier than other researchers mentioned, Shirley hypothesized that linguistic development is held in "abeyance" at the time when motor progress is rapid. Gessell stated that motor and language development does not proceed at the same pace, but, instead, while one system develops vigorously, the other may be held dormant, and vice versa. According to Lenneberg's model, there is a "synchronization" of language and motor milestones. Lenneberg stressed that language onset is not a consequence of motor control, but each skill develops independently (Hopper and Naremore, 1973).

\section{Motor Development}

The second through the seventh years is considered the most critical period for normal motor development (McClenaghan and Gallahue, 1978). By the end of the second year the child has mastered the "rudimentary movement abilities" that are developed during infancy. These movements form the basis on which the child develops "fundamental movement patterns" of early childhood. At three years, according to wood (1964), a child has temporarily mastered gross and fine motor skills, but at four years of age much of the coordination mastered in the past becomes disrupted and he may appear poorly coordinated. By the age of five or six years, McClenaghan and Gallahue have observed that the child's movements are ". • 
mechanically efficient, coordinated, and controlled performances." For normal motoric development, the child must have quality and a variety of movement experiences.

\section{Related Studies}

It would appear the theories postulated by Kephart (1960), Barsch (1966), Lenneberg (1967), and Delacato (1973), have served as basic foundations by which further studies have been conducted. Researchers have taken an interest in correlating motor skills with articulation disorders (Jenkins and Lohr, 1964; Powers, 1971; and Sommers and Kane, 1974); oral and verbal diadokokinetic rates (Fletcher, 1972); learning disabilities (Turton, 1975; and Bruininks, 1978); and mental retardation (Ismail, Kephart, and Cowell, 1963; and Myklebust, 1971). The present study is more concerned with language. Researchers have found limited studies correlating motor skills with language or language delays.

Researchers have sought to find an interrelationship between language and motor skills other than known developmental patterns cited in the literature (Sprague, 1961). Sprague conducted a study using 62 eight year old boys with normal language. The purpose of the study was to determine how expressive language skills were related to motor skills. Expressive language skills were measured by Mean Length of Response (MLR), Mean of the Five Longest Response (M5L), Number of One Word Responses (NIW), Structural Complexity of Response (SCS), and Number of Different Words Used in Response 
(NDW). The measures of motor skills included Running, Stick Balance, Throwing, Jumping, and Manual Dexterity (Placing and Turning). There were correlations beyond the .05 level of probability with the manual dexterity items. According to the data, NIW was the only expressive language measurement which showed a significant negative correlation, ( $r=-.28$ ) with Placing. This means the subjects' performance scores were low on the Placing task and high on the NIW expressive language measurement. M5L $\left(r_{0}=+.18\right), \operatorname{SCS}(r .=+.06), \operatorname{MLR}$ $\left(r_{.}=+.18\right)$, and NDW $\left(r_{0}=+.18\right)$, did not reach statistical significance with the Placing task. Turning showed significant positive correlations with M5L $\left(r_{0}=+.28\right)$, and NDW $(r .=+.29)$, while NIW showed a negative correlation $\left(r_{.}=-.30\right)$ with Turning. $\operatorname{MLR}\left(r_{0}=+.21\right.$ and $\operatorname{SCS}\left(r_{0}=+.10\right)$ were not highly correlated with Turning. In regard to the gross motor items, Sprague did not find correlations with MLR, M5L, SCS, NDW, or NIW. Therefore, Sprague concluded there were correlations between measures of expressive language and manual dexterity but not between gross motor skills and expressive langauge.

According to Luria (1961), after four and one-half years of age a child begins to use his internalized verbal system to organize sequences of motor activity. In addition, the differences in the quality and quantity of verbal output should correspond to analogous attributes of motor behavior. The investigator observed and analyzed "retarded speech" and motor actions of identical twins. The pair was observed 
while interacting with other children of the same age during play activities. Observation of the twins indicated they did not participate in mobile action games, such as, chasing and catching. The twins' drawings, paintings, and building with blocks were below the age level of other playmates the same chronological age. Luria concluded the twins were unable to engage in productive, complex motor activity due to limited internal operations. In a follow-up experiment, language management was given to one of the twins. The other twin did not have language management. Each session focused on increasing sentence development. Three months later, the twins were observed. Results indicated speech improvement as well as meaningful, constructive, motor activity in the one twin who participated in language management. Not only did the child develop new forms of verbal communication, but significant changes were evident in the structure of conscious activity, built on the basis of verbal speech. The other twin, without langauge management, appeared to have no changes in motor skills or verbal communication. As a result of the study, the investigator noted a possible interrelationship between a child's motor actions and his quality of expressive communication.

Wolff and Wolff (1972) examined the correspondence between quantity and sophistication of verbal output and the child's production of gross and fine motor movements. In the study, the investigators used three groups of normal language developing children four through five years of age with each 
group consisting of 23,17 , and 15 children respectively. The children were assessed by their teachers on the basis of perceived verbal output ("talkativeness"), verbal skills ("the level of sophistication"), gross and fine motor activity, and manual dexterity. The investigators found high correlations between the quantity of verbal output and the quantity of gross motor activity $\left(r_{0}=+.596\right)$; whereas, verbal skills were not significantly related to gross motor activity $(r .=+.007)$. Ratings on fine motor and manual dexterity tasks, however, were significantly related to verbal skills $(r .=+.668$ and +.556 , respectively). Fine motor and manual dexterity were more highly related to verbal skills than to verbal output ( $p>.025$ in each dimension). Verbal output is more highly related to gross motor than to fine motor ( $p>.14$ ), or to manual dexterity $(p>.026)$. Conversely, verbal skills are more highly correlated with both fine motor and manual dexterity than with gross motor (both p's >.001). The correlation of verbal skills with verbal output is lower than either fine motor $(p>.024)$ or manual dexterity $(p>.073)$. In general, the results of the Wolff and Wolff study indicated that while incidence of gross motor activity is associated primarily with quantity of speech output, degree and incidence of fine manipulative activity is more related to degree of verbal sophistication. Wolff and Wolff stated that,".. these correlations are consistent with the clinical observations of Luria and Yudovich (1959) that quality of verbal output mirrors quality of motor activity. Needless to say, no 
casual relationships are implied by the present results."

\section{Summary}

Within the field of Speech-Language Pathology, researchers have hypothesized an interrelationship between motor skills and articulation disorders, oral diadokokinetic rates, learning disabilities, and mental retardation. Relatively few studies have correlated motor skills and expressive language delay in children. Since Speech-Langauge Pathologists have had an increased concern in language, normal and disordered, it is important to determine if a correlation exists between expressive langauge delay and motor abilities. It also is important to isolate specific motor variables most affected within the population. 
CHAPTER III

METHODS AND PROCEDURES

Methods

$\underline{\text { Subjects }}$

Twenty children, ranging in age from five years through six years, eleven months with a diagnosis of an expressive language delay of twelve months or more, were chosen to participate in this investigation. The mean age of the group was five years, eight months. Their diagnosis was based on the Individual Educational Program completed by an oregon certified Speech-Language Pathologist. The children were selected from the public schools in the greater Portland area.

\section{$\underline{\text { Screening }}$}

Children who met the above stated criteria and returned the parent permission forms (see Appendix A) participated in screening procedures, which included: a pure-tone, audiometric screening test at 25 dBHL for the frequencies of 500, 1000,2000 , and $4000 \mathrm{~Hz}$; and, Form L of the Peabody Picture Vocabulary Test-(PPVT) Revised (Dunn, 1981). Each candidate had normal hearing acuity in the better ear and a receptive language age within two standard deviations of their chronological age. In addition, the subjects had no broken bones, 
sprained limbs, or any other motor dysfunctions.

Instruments

The Preschool Language Scale. The expressive portion of the Preschool Language Scale-PLS (zimmerman, Steiner, and Evatt, 1969) was utilized to measure expressive language skills. The PLS was designed as an evaluation instrument for isolating strengths and weaknesses in receptive and expressive language skills for children one year, six months, to seven years of age. The PLS has individual subtests assessing "Auditory Comprehension Ability" (AC) and "Verbal Ability" (VA). For the purposes of this study, the VA was utilized. A total of eighty items are included throughout the VA and AC subtests, with forty items in each subtest. The concepts measured are: logical thinking; sensory discrimination; grammar; vocabulary; memory; attention span; and temporal and spatial relations. The VA scale measures articulation as well.

Each item has a specified passing criteria described in the test manual and test form. Initially, the child is tested at an age level below his estimated ability. Basal age is established when four test items at a given age level are correct. Testing continues until all test items at an age level are missed. From the basal age score, language age equivalents for both $A C$ and VA may be determined. In addition, $A C$ and $V A$ quotients and an overall Language Age are established. For the purposes of this study only a VA age 
equivalent was determined for each child.

The PLS has a reliability rating of .88 , using a splithalf reliability coefficient. Concurrent validity was established by correlating the PLS with scores on the Illinois Test of Psycholinguistic Ability-(ITPA), Utah Test of Language Development-(UTLD), and the Peabody Picture Vocabulary Test(PPVT) . Higbee (1974) administered the ITPA and the PLS to a sample of cerebral palsied children aged 4 to 10 years old, with a Pearson correlation coefficient ranging from .94 to .99. Scott (1973) assessed thirty-two middle-class children, aged three to four years, using the UTLD and the PLS. The Pearson correlation coefficient was .70. Zimmerman and Steiner (1971) assessed twenty-five Head start children using the PPVT and the PLS with a Pearson correlation coefficient ranging from .66 to .68 .

The Bruininks-Oseretsky Test of Motor Proficiency. The short form of the Bruininks-Oseretsky Test of Motor Proficiency-(BOMP) (Bruininks, 1978) was used to measure each subject's motor skills. The test was designed to assess both gross and fine motor skills in children four years, six months, to fourteen years, six months. Bruininks based part of the test on the United States adaptation of the Oseretsky Test of Motor Proficiency (Doll, 1946). The items in the original Oseretsky test were evaluated according to criteria established to guide both selection of old items and the development of new items. Bruininks divided the test into 
eight subtests, including: four gross motor sections (running speed and agility, balance, bilateral coordination, and strength); three fine motor sections (response speed, visual motor control, and upper-limb speed and dexterity); and one subtest assessing both gross and fine motor skills (upperlimb coordination).

The complete form of the test consists of forty-six test items, fourteen of which make up the short form. Since many items on the test require using arm or leg preference, Bruininks includes a pretest. This portion of the BOMP is not considered in the final scoring and anlysis. All of the items on the short form are administered to each child as presented in the manual. At the end of testing, scores are totaled and converted into percentile ranks, standard scores, and stanine scores.

The reliability rating for the BOMP was determined by test-retest from 63 second graders and 63 sixth graders. Test-retest reliability for the gross motor composite was .77 , .88 for the fine motor composite, .89 for the battery composite, and .87 for the short form.

\section{Procedures}

Each child meeting subject and screening criteria was given the PLS and the BOMP in a quiet classroom. Prior to test administration, furniture was rearranged to clear a large area for the motor task performances on the BOMP. Initially, rapport was established with each child by engaging 
in a two minute conversation with the investigator. The expressive portion of the PLS was given with the child seated at a table across from the examiner. The test was administered according to the instructions and criteria stated in the manual. When basal and ceiling ages were established, each child received a three minute rest period.

Prior to administering the short form of the BOMP, each child performed two tasks presented in the pretest following the tester's demonstration. All instructions on the pretest and the short form were read as stated in the manual. As the items were performed by the children, they were scored according to the criteria described. Positive reinforcement, such as "good listening" and "nice sitting," was given throughout the testing situation. Together, the PLS and the BOMP took approximately forty-five minutes to administer to each child.

Reliability of Data

Inter-judge reliability on the expressive portion of the PLS was established between this investigator and a previous graduate student from the Speech and Hearing sciences Program at Portland State University. To establish interjudge reliability, five children ranging in age from five years through six years, eleven months, were randomly chosen from the Helen Gordon Child Care Center. Initially, the investigator set-up a training session with the judge to review the test, including the administration, scoring, and 
evaluation procedures. Following the training session, each child was administered the PLS by the investigator. The responses were scored and analyzed by the investigator and the judge, with an inter-judge reliability score of 1.00 .

Intra-judge reliability was established by the investigator one week following the inter-judge reliability testing. Each child was individually tested according to the procedures stated in the manual. After the responses were scored and analyzed, the investigator compared the scores with the inter-judge reliability test scores. Intra-judge reliability was determined to be .80 . The intra-judge score for the independent judge was .90 .

Inter-judge reliability on the short form of the BOMP was established between this investigator and an instructor at Portland State University who was proficient in administering the test. The instructor and investigator, for calibration purposes, reveiwed the administration, scoring, and analysis of the BOMP. Following the training session, the short form of the BOMP was administered to two children with the same age range used to establish reliability for the PLS. The BOMP was administered, scored, and analyzed by the investigator and the independent judge with a reliability coefficient of .90 .

Intra-judge reliability for the BOMP was established by the investigator one week following the inter-judge reliability testing. The test was administered, scored, and analyzed according to the test manual. The investigator compared these 
scores with the scores from the inter-judge reliability rating. Intra-judge reliability was determined to be 1.00 . The intra-judge score for the independent judge was 1.00 .

\section{Analysis of Data}

The Pearson Product-Moment Correlation coefficient (r.) was used to determine the association between the subjects' Verbal Ability Age on the PLS and the motor performance scores on the BOMP. Means and standard deviations were computed for each variable on the BOMP as well. One-tailed ttests were implemented to assess the significance of the Pearson Product-Moment Correlation with eighteen degrees of freedom, and a probability level of .05. 
CHAPTER IV

RESULTS AND DISCUSSION

Results

The purpose of the present investigation was to determine the association between expressive language delay in children and their motor abilities. Specifically, the study assessed expressive language using the "Verbal Ability" portion of the Preschool Language Scale-PLS (Zimmerman, et al., 1969), and the short form of the Bruininks-Oseretsky Test of Motor Proficiency-BOMP (Bruininks, 1978). Twenty children were selected to participate in the study, ranging in age from five years through six years, eleven months. The mean chronological age of the population was 67 months with a standard deviation of 4.47 months (see Table I). The expressive language age delay ranged from 12-30 months, with a mean of 18.5 months and a standard deviation of 4.69 months.

The first question posed was: Is there a significant relationship between an increased expressive language delay and reduced motor abilities in children with a language delay? A Pearson Product-Moment correlation Coefficient was used to determine the extent of association between the subjects' expressive language age delay on the PLS and the "Motor Scores" on the BOMP. In addition, a one-tailed t-test was computed 


\section{TABLE I}

MEAN AND STANDARD DEVIATION OF THE SAMPLE'S CHRONOLOGICAI AGE IN COMPARISON TO THE EXPRESSIVE LANGUAGE AGE DELAY, MEAN AND STANDARD DEVIATION AS MEASURED BY THE PLS

\begin{tabular}{|c|c|c|c|c|}
\hline \multicolumn{2}{|c|}{ Chronological Age } & Preschool & Language & Scale \\
\hline$\overline{\mathrm{x}}$ & $S D$ & Range of Delay & $\overline{\mathrm{x}}$ & $S D$ \\
\hline $67 *$ & 4.47 & $12-30 *$ & 18.5 & 4.69 \\
\hline
\end{tabular}

* figures represent months

for each correlation coefficient to determine the statistical significance of the $r$. values in the predicted (negative) direction. The Standard Score was 44.50 with a standard deviation of 8.92 (Table II). The Total Point score produced a mean of 24.25, and a standard deviation of 7.94. The mean of the Percentile Rank was 34.40 with a standard deviation of 25.64. Table II also reports the correlation between the subjects' language age delay and "Motor Scores." All three correlations were in the expected direction; however, only the standard score generated correlation was of at least moderate strength (see Appendix C), r. $=-.41, p_{.}>.05$. The Total Point Score generated a slight inverse correlation, r. = -.17, while the Percentile Rank posted a low correlation, $r .=-.27$. In answer to the first question, then, there is a slight to moderate inverse correlation between expressive language delay in children and their motor abilities. 
TABLE II

MEAN, STANDARD DEVIATION, ANALYSIS OF CORRELATION

BETWEEN THE PLS AND THE BOMP, AND t-TEST

RESULTS

\begin{tabular}{|c|c|c|c|c|}
\hline $\begin{array}{c}\text { Bruininks-Oseretsky } \\
\text { Test of Motor } \\
\text { Proficiency }\end{array}$ & $\overline{\mathrm{x}}$ & $\mathrm{SD}$ & $r$. & $t-\operatorname{tes}^{a}$ \\
\hline Total Point score & 24.25 & 7.94 & -0.17 & .732 \\
\hline Standard Score & 44.50 & 8.92 & -0.41 & $1.906 *$ \\
\hline Percentile Rank & 34.40 & 25.64 & -0.27 & 1.189 \\
\hline
\end{tabular}

The second question posed was: What specific gross and fine motor skills had the strongest association with expressive language delay? Table III shows the point score ranges, means, standard deviations, correlations, and $\underline{t}$-test results on the items from the short form of the BOMP. It can be seen there are negligible correlations in many of the gross motor items. Three out of six fine motor test items, however, had slight to moderate negative correlation coefficients. Item 11, "Copying a Circle," had a moderately-strong inverse correlation with language age delay $\left(r_{0}=-.48\right)$, but item 9 posted a low correlation $(r .=-.24)$, and item 12 generated a slight correlation $\left(r_{0}=-.37\right)$. This means the children with low expressive language abilities demonstrated lower performance on "Copying a Circle" than "Response speed," or "Copying Overlapping Pencils." "Copying a Circle" was the only test 


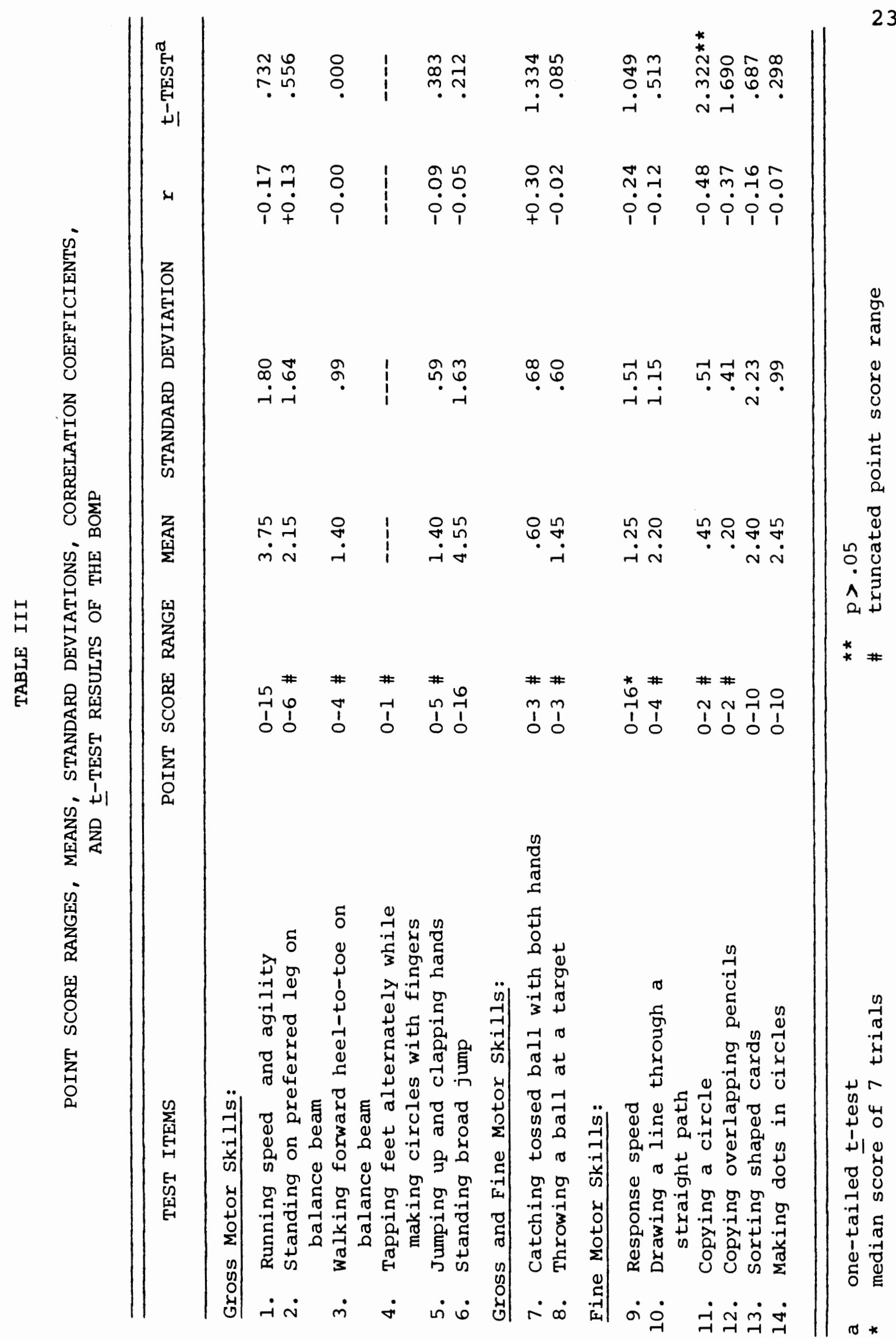


item generating a moderate correlation with expressive language delay, and hence, a significant association beyond the .05 alpha level. "Copying Overlapping Pencils" registered just below the .05 alpha level.

Further inspection of Table III shows two items with positive correlations, contrary to expectations. Item 2, "Walking Heel-to-Toe on a Balance Beam," and item 6, "Catching a Tossed Ball," had slight to low positive correlations, r. $=+13$ and +.30 , respectively. This means the children with high language age delay tended to demonstrate an increase in performance scores on "Walking Heel-to-Toe on a Balance Beam," and "Catching a Tossed Ball."

In answer to question two, then, "Copying a Circle," "Copying Overlapping Pencils," and "Response Speed" registered the strongest correlations with expressive language age delay in the expected direction (inverse), with "Copying a Circle," showing the strongest correlation, $r .=-.48$, with expressive language delay.

In summary, the data of the present study indicate that expressive language delayed children demonstrated slight to moderate fine motor coordination deficits. On-the-other-hand, expressive language delayed children definitely do not appear to have marked deficits in gross motor coordination, especialIy with "Catching A Ball" and Walking Heel-to-Toe."

\section{DISCUSSION}

According to test results for the first question posed, 
expressive language delay in children tends to be associated with reduced motor skills, as measured by the Standard Score of the BOMP. Except for Luria (1961), other studies have not measured motor skills in terms of overall abilities, but instead assess individual motor skill items which correlate with language abilities. In this study, not only were individual items correlated, but an overall measurement, the Standard Score, was used as a means to correlate a child's motor skills, which encompass both gross and fine motor abilities in the several subtest items.

The results of the Standard Score (refer to Table II) support the concluding observations made by Luria (1961). He suggested a possible interrelationship between a child's motor skills and his quality of communication. The size, age, and experimental design differed from the present study. Luria's study used two identical twins, 4.5 years of age with "retarded speech." The present investigation, however, included twenty children, 5.0 through 6.11 years of age, with expressive language delay.

Luria (1961) assessed the twins' motor skills based on observational procedures. They were placed in a setting with other age-mates and were given toys including paper, pencils, paints, and building blocks. In contrast, the experimental design of the current study included two standardized tests, the BOMP and the PIS. Even though there were methodology differences between Luria's study and the present study, the concluding observations by Luria were appropriate for 
comparison in the present study.

The results of the second question posed in the current investigation indicated a tendency for language delayed children to have reduced, fine motor skills. The results of the present study are compatible with earlier studies. Sprague (1961) found correlations beyond the .05 alpha level between manual dexterity tasks, "Placing" and "Turning," and expressive language. According to the data, NIW (Number of one Word Responses) indicated a weak inverse correlation ( $r$. = -.28) with the "Placing" task, while MLR (Mean Length of Resporise), M5L (Mean of the Five Longest Responses), SCS (Structural Complexity of Response), and NDW (Number of Different Words used in Response), registered negligible correlations, r. $=+.08,+.18,+.06,+.18$, respectively. "Turning," also classified as a manual dexterity item, showed significant correlations with M5L $\left(r_{.}=+.28\right), \mathrm{NIW}\left(r_{.}=-.30\right)$, and NDW $\left(r_{.}=+.29\right)$. Significant correlations were not obtained with $\operatorname{MLR}\left(r_{0}=+.21\right)$ and $\operatorname{sCS}\left(r_{0}=+.10\right)$. Negligible correlations were found between each of the expressive language measures and all of the gross motor task items, which included: Running, Stick Balance, Jumping, and Throwing. In Sprague's study (1961), correlations were found between "Placing" and "Turning," manual dexterity tasks, and expressive language. Negligible correlations were evident between measures of gross motor skills and measures of expressive language. The data presented in this study appear to support sprague's findings correlating expressive language and fine motor skills. 
The results of the current study tend to be compatible with the Wolff and Wolff study (1972) as well. Although due to methodology differences a one-to-one relationship with the present study is not possible. Wolff and Wolff used teacher rating scales to collect data, while the current study used standardized tests for data collection purposes. This investigator found a negligible correlation (see Table III) between gross motor skills and expressive language delay. According to Wolff and Wolff, verbal skills (sophistication of language) were not significantly correlated with gross motor skills $(r .=.007)$. Fine motor and manual dexterity tasks, however, were significantly correlated with verbal skills, $r .=.668$, and .556 , respectively. In the present study there was a significant correlation between expressive language delay and fine motor skills. Three out of six fine motor itmes had moderate to weak inverse correlations (see Table III). "Copying a Circle," which Bruininks (1978) classifies as a manual dexterity task, registered the only moderate inverse correlation, $r .=-.48$. "Copying Overlapping Pencils," also a manual dexterity task, $r .=.37$ registered a low inverse correlation.

A possible explanation for the correlations obtained in the present investigation might be due to maturation. According to Williams (1982), the ability to copy forms from visual models is "nearly mature" at the age of nine, with most growth occurring between ages five through seven. It would appear, then, that the children in the present investigation had not 
fully developed the ability to copy forms appropriately from a visual model. Therefore, the children would not achieve a maximum point score. In other words, their motor skills were impeded, or beyond the appropriate age level.

The children's motivation also might be a possible explanation for the lower performance scores on items 11 and 12, manual dexterity tasks. From observation, it appeared to this investigator that the subjects were more willing and motivated to perform gross motor tasks than fine motor tasks. Although this might also have been true with the standardization group of the BOMP. The performance scores in the present study might have reflected the children's motivational level throughout the assessment.

In the gross motor subtest, items 2, "Walking Heel-toToe on a Balance Beam," and item 7, "Catching a Tossed Ball," had weak positive correlations, $r_{.}=+.17$, and +.30 , respectively. This is contrary to the expected outcome. Cultural factors might account for these correlations. The society in the United States appears to encourage children to learn how to catch balls, perform balancing acts, etcetera, which can be observed not only in parent-child interaction and play activity with siblings but with age-mates, during physical education classes and at school.

It also should be noted that six test items on the short form of the BOMP had truncated point score ranges (Table III). Due to the narrow point score ranges of these items, there is an underestimated magnitude of the correlations. If the point 
score ranges were increased, it is predicted that the correlations between the expressive language age delay and the motor skills might increase.

In general, most of the activities in the gross motor subtest of the BOMP primarily involve the child's entire body in space. The fine motor subtests, however, require precise movements. Along these lines, expressive language partly involves fine motor control of the speech musculature. The quality of language, then is partially dependent on the child's ability to move the speech musculature, which requires similar precise movements. Therefore, one would not expect to see correlations between gross motor skills, and expressive language delay, but correlations between fine motor skills and expressive language delay would appear to be plausible. In summary, there was a negligible inverse correlation between expressive language delay and gross motor skills. In relation to the fine motor skills, on the other hand, three out of six items had a low or moderate inverse correlation. There appears to be an indication for language delayed children to have greater difficulty with fine motor tasks than gross motor tasks. In the present study, the population's performance on manual dexterity items, in the fine motor subtest, appeared to be lower, and more difficult than the items on the gross motor subtest. 


\section{CHAPTER V}

\section{SUMMARY AND IMPLICATIONS}

\section{Summary}

Lenneberg (1967) noted that as a child matures a general growth pattern is observed with both language skills and motor skills co-developing. Most of the research relating to motor skills deals with articulation skills, oral diadokokinetic rates, learning disabilities, and intelligence. Relatively few studies, however, appear to correlate motor skills with expressive language delay in children.

The purpose of the present study was to determine the correlation between expressive language delay in children and their gross and fine motor skills. Twenty children, five years through six years, eleven months with a diagnosed expressive language delay, were selected to participate in the study. Each was screened on the basis of normal hearing, receptive vocabulary skills, motor functioning, and an expressive language delay of one year or more. After screening procedures, each child was administered the Preschool Language Scale-PLS (Zimmerman, et al., 1969) and the short form of the Bruininks-Oseretsky Test of Motor Proficiency-BOMP (Bruininks, 1978). The data were analyzed using a Pearson Product-Moment Correlation along with means, standard deviations, and a 
one-tailed $\underline{t}$-test of significance.

According to the data results, the Standard Score, an overall measurement of the children's motor skills, indicated a moderate inverse correlation, $r_{0}=-.41$, while the Total Point Score, $r_{0}=-.17$, and the Percentile Rank, r. $=-.28$, had weak inverse correlations. In relation to the individual test items, negligible correlations were indicated in the gross motor items, "Walking Heel-to-Toe," and "Catching a Tossed Ball," classified as gross motor tasks, obtained positive correlation, $r_{.}=+.13$, and +.30 , respectively.

There were three out of six fine motor tasks with low to moderate inverse correlations: "Copying a Circle" generated a moderately-strong inverse correlation, $r=-.48$; "Copying Overlapping Pencils," and Response Speed," posted low inverse correlations, $r_{0}=-.37$ and $r_{0}=-.24$, respectively. A one-tailed $t$-test revealed subjects performed these three items more poorly than the gross motor and some fine motor tasks on the BOMP. The expressive language delayed children tended to have deficits in manual dexterity tasks but not in gross motor tasks.

The results obtained from the present study were compatible with the research conducted by sprague (1961) and Wolff and Wolff (1972). Both investigators found significant correlations between fine motor tasks and expressive language. Negligible correlations were indicated between gross motor skills and expressive language. It was concluded by the present investigator that children with expressive language delay 
might have deficient fine motor development.

\section{Implications}

$\underline{\text { Research }}$

Further investigations correlating expressive language delay with motor abilities is warranted. In this study, the short form of the BOMP was used as a means of assessing the children's motor skills. For more valid results, the complete battery of the BOMP should possibly be used. The long form includes eight subtests with forty-six test items. The short form includes eight subtests and fourteen test items. In addition, the long form has normative data, age equivalents, standard scores, and percentile ranks. By using the complete battery, perhaps the investigator could determine additional skills which correlate with the subjects' language age delay. The investigation included a limited number of subjects (20) with a narrow age range. It may be of interest in further studies to have a larger number of language delayed subjects with cells of different age groups, encompassing the age range five years through fourteen years. The performance of the older children in fine motor tasks might yield different results than the younger children. The results of the study should determine whether or not the older children have low performance in the same skill areas as the younger children. Furthermore, determine which motor skill areas each of the age groups appear to have difficulty in performing. 


\section{Clinical}

There is an increasing need for Speech-Language Pathologists to not only focus on a child's speech and language, but to have an overall awareness of his total development. This is especially important in the public school setting. The results of the present study may be of further assistance to the Speech-Language Pathologist in diagnosing a child with an expressive language delay. Their input on the child's motor skills in relation to language skills would be valuable information, especially within a multidisciplinary team.

From the evidence discussed in the current investigation, it is apparent that children with expressive language delay tend to have fine motor deficits, but not gross motor deficits. Intervention techniques using gross motor tasks with language delayed children need to be reviewed with more emphasis placed on fine motor tasks, such as drawing, tracing around shapes, copying shapes from a visual model, etcetera. By using these techniques, both a child's language skills and fine motor skills might be stimulated together. 


\section{REFERENCES}

BANGS, T. Language and learning disorders of pre-academic children, with curriculum guide. New York: AppletonCentury Crofts, Inc., 1968.

BARSCH, R.H. Teacher needs-motor training. In W. Cruikshank (Ed.). The teacher of brain-injured children. Syracruse, N.Y.: Syracruse University Press, 1966.

BRUININKS, R.H. Bruininks-oseretsky test of motor proficiency. Circle Pines, Minnesota: American Guidance Service, 1978.

DELACATO, C.H. The diagnosis and treatment of speech and reading problems. Springfield, Illinois: Charles $C$. Thomas, 1973.

DOLL, E.A. The Oseretsky tests of motor proficiency: a translation from the Portuguese adaptation. Minneapolis, Minnesota: Educational Test Bureau, 1946.

DUNN, L.M. The Peabody Picture Vocabulary Test-Revised. Circle Pines, Minnesota: American Guidance Service, 1981 .

FLETCHER, S.G. Speech as an element in organization of motor response. Journal of Speech and Hearing Research. $1972,5,29 \overline{2-300}$.

GESSELL, A. The ontogenesis of infant behavior. In L. Carmichael (Ed.), Manual of Child Psychology (2nd Ed.). New York: John Wiley and Sons, 1954 .

GUILFORD, J.P. Fundamental Statistics in Psychology and Education. New York: McGraw-Hill, Inc., 1956.

HIGBEE, N.L. A comparative study of the Preschool Language Scale and the Illinois Test of Psycholinguistic Ability when administered to a population of cerebral palsied children. Master's thesis, University of Southern California, Los Angeles, Calif., 1974.

HOPPER, R. and NAREMORE, R.C. Children's Speech: A practical introduction to communication development. New York: Harper Row, 1973. 
ISMAIL, A., KEPHART, N., and COWELL, C.C. Utilization of motor aptitude tests in predicting academic achievement. Technical Report No. 1. Indiana: Purdue University Research Foundation, 1963.

JENKINS, E., and LOHR, R.E. Severe articulation disorders and motor ability. Journal of Speech and Hearing Disorders. $1964,29,2 \overline{86-292}$.

KEPHART, N.C. The slow learner in the classroom. Columbus, Ohio: Charles E. Merrill, 1960.

LENNEBERG, E.H. Biological foundations of language. New York: John Wiley and Sons, Inc., 1967.

LURIA, A.R. The role of speech in the regulation of normal and abnormal behavior. New York: Liveright, 1961.

LURIA, A.R., and YUDOVICH, R.IA. Speech and the development of Mental Processes in the child. London: Staples Press, 1959.

MCCARTHY, D. Language Development in Children. In L. Carmichael (Ed.), Manual of Child Psychology. New York: John Wiley and Sons, 1946.

MCCLENAGHAN, B.A., and GALLAHUE, D.L. Fundamental Movement. Philadelphia: W.B. Saunders Co., 1978 .

MENYUK, P. The acquisition and development of language. Englewood Cliffs, New Jersey: Prentice-Hall, Inc., 1971 .

MYKLEBUST, H.R. Development and disorders of written language. New York: Grune and Stratton, 1971.

ORTON, S.T. Reading, writing, and speech problems in children. New York: Norton, and Co., Inc., 1937.

POWERS, M.H. Functional disorders of articulation sympotomatology and etiology. In L.E. Travis (Ed.), Handbook of Speech Pathology and Audiology. New York: AppletonCentury-Crofts, 1971 .

SAGE, G.H. Introduction to motor behavior: A neuropsychological approach. Massachusettes: Addison-Wesley Publishing Co., Inc., 1977.

SCOTT, G.H. A comparison of the Utah Test of Language Development and the Preschool Language Scale. Master's thesis, Illinois state University, Normal, Illinois, 1973 . 
SHIRLEY, M.M. The first two years, a study of 25 babies. Vol. II, Intellectual development. Institute of Child Welfare Monographs. Minneapolis: University of Minnesota Press, 1933.

SOMMERS, R., and KANE, A. Nature and remediation of functional articulation disorders. In Dickson, S. (Ed.), Communication disorders: remedial principles and practices. Glenview, Illinois: Scott, Foresman and Co., $\overline{1974 .}$

SPRAGUE, A.L. The relationship between selected measures of expressive language and motor skill in eight-year old boys. Doctoral dissertaion, State University of Iowa, Iowa City, Iowa, 1961.

TURTON, L.J. Developmental and linguistic aspects of learning disabilities. In Cruikshank, W.M. and Hallahan, D.P. (Eds.), Perceptual and learning disabilities in children. New York: Syracruse University Press, 1975.

WILLIAMS, H.G. Perceptual Motor Development. Englewood Cliffs, New Jersey: Prentice-Hall, Inc., 1982.

WOLFF, P. and WOLFF, E. Correlational analysis of motor and verbal activity in young children. Child Development. $1972,43,1407-1411$.

WOOD, N.E. Delayed speech and language development. Englewood Cliffs, New Jersey: Prentice-Hall, Inc., 1964.

ZIMMERMAN, I.L., STEINER, V.G. and EVATT, R.L. Preschool Language Manual. Columbus, Ohio: Charles E. Merrill, 1969 .

ZIMMERMAN, I.L. and STEINER, V.G. A comparative study of the Preschool Language Scale and the Peabody Picture Vocabulary Test. Paper presented at the California Association of School Psychologists and Psychomotrists/National Association of School Psychologists. San Francisco, California, 1971. 


\section{APPENDIX A}

\section{PARENT PERMISSION FORM}

Dear Parent or Guardian,

My name is Gail Cunningham. I am a second year graduate student at Portland State University in Speech-Language Pathology, and currently involved with a research project. The purpose of my study is to determine the relationship that exists between a child's language delay and his motor abilities (i.e., running, jumping, pencil tracing, response speed, etc.). The term "language delay," in this study, refers to language which follows a normal pattern of development, but is below age level according to the child's age. Twenty children, kindergarten through first grade, will be needed to run the study.

In my study, I will use a language test, the Preschool Language scale, which looks at a child's spoken language, and the Bruininks-oseretsky Test of Motor Proficiency, which looks at a child's gross motor (running, jumping, catching a ball) and fine motor skills (tracing, response speed, making pencil dots). The children will be tested individually in two 30 minute sessions. I would like your permission to include your child in this study. The name of your child and the test scores will be kept in strictest confidence. The name of your child will not be used in the written portion of the study. If your child does not wish to participate, he/she may leave voluntarily.

Please complete the letter below indicating your approval, and return with your child to school tomorrow.

I, , agree to let my child, - participate in Gail Cunning-

ham's study.

\section{Date}

Thank you for your cooperation. 


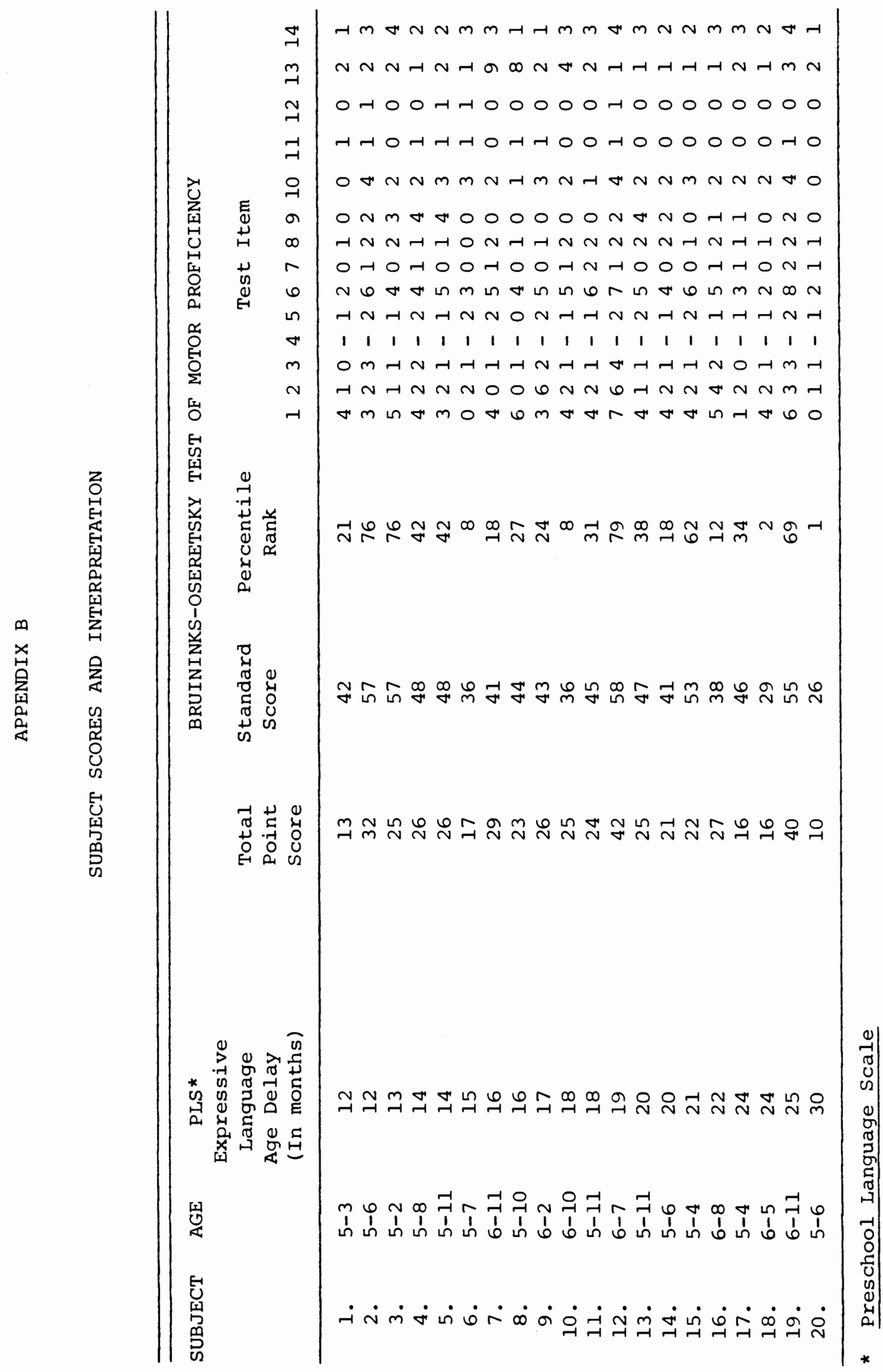




\section{APPENDIX C}

\section{VALUE GUIDELINE OF PEARSON PRODUCT-MOMENT CORRELATION COEFFICIENT}

$<.20$ slight; almost negligible correlation

.20-.40 low correlation; definite but small relationship

$.40-.70$ moderate correlation; substantial relationship

.70-.90 high correlation; marked relationship

(Guilford, 1956) 